\title{
Fluoxetine prevents development of an early stress-related molecular signature in the rat infralimbic medial prefrontal cortex. Implications for depression?
}

Rafael A Barreto ${ }^{1,2,3}$, Frederick Rohan Walker ${ }^{1,2,3}$, Peter R Dunkley ${ }^{1,2,3}$, Trevor A Day ${ }^{1,2,3,4}$ and Doug W Smith ${ }^{1,2,3^{*}}$

\begin{abstract}
Background: Psychological stress, particularly in chronic form, can lead to mood and cognitive dysfunction and is a major risk factor in the development of depressive states. How stress affects the brain to cause psychopathologies is incompletely understood. We sought to characterise potential depression related mechanisms by analysing gene expression and molecular pathways in the infralimbic medial prefrontal cortex (ILmPFC), following a repeated psychological stress paradigm. The ILmPFC is thought to be involved in the processing of emotionally contextual information and in orchestrating the related autonomic responses, and it is one of the brain regions implicated in both stress responses and depression.
\end{abstract}

Results: Genome-wide microarray analysis of gene expression showed sub-chronic restraint stress resulted predominantly in a reduction in transcripts 24 hours after the last stress episode, with 239 genes significantly decreased, while just 24 genes had increased transcript abundance. Molecular pathway analysis using DAVID identified 8 pathways that were significantly enriched in the differentially expressed gene list, with genes belonging to the brain-derived neurotrophic factor - neurotrophin receptor tyrosine kinase 2 (BDNF-Ntrk2) pathway most enriched. Of the three intracellular signalling pathways that are downstream of Ntrk2, real-time quantitative PCR confirmed that only the PI3K-AKT-GSK3B and MAPKJERK pathways were affected by sub-chronic stress, with the PLC $\gamma$ pathway unaffected. Interestingly, chronic antidepressant treatment with the selective serotonin reuptake inhibitor, fluoxetine, prevented the stress-induced Ntrk2 and PI3K pathway changes, but it had no effect on the MAPKJERK pathway.

Conclusions: These findings indicate that abnormal BDNF-Ntrk2 signalling may manifest at a relatively early time point, and is consistent with a molecular signature of depression developing well before depression-like behaviours occur. Targeting this pathway prophylactically, particularly in depression-susceptible individuals, may be of therapeutic benefit.

Keywords: Neurotrophin, Gene expression, Microrarray, Restraint stress, Signalling pathways

\footnotetext{
* Correspondence: Douglas.smith@newcastle.edu.au

'School of Biomedical Sciences and Pharmacy Faculty of Health, University of

Newcastle, Callaghan, NSW 2308, Australia

${ }^{2}$ Priority Research Centre for Translational Neuroscience and Mental Health,

University of Newcastle, Callaghan, NSW 2308, Australia

Full list of author information is available at the end of the article
} 


\section{Background}

Stress is a potent risk factor in the development of mood and anxiety disorders and other psychopathologies. For example, stress is an important non-genetic cause of major depressive disorder (MDD), with both acute and chronic forms capable of precipitating major depressive episodes [1,2]. A number of theories have been proposed to explain how stress alters brain structure and function in stress responsive areas [3] and there is compelling evidence for synaptic plasticity dysregulation, with much work having elucidated how the glucocorticoid and various neurotransmitter systems contribute to this dysregulation (for reviews see [4-9]). In order to better understand how stress affects brain function, we have previously used a chronic psychological stress model and found that this stress paradigm markedly upregulates deltaFosB expression, a marker of ongoing neuronal activity, in the infralimbic medial prefrontal cortex (ILmPFC) [10]. The ILmPFC is implicated in processing emotional context and, consistent with this notion, human patients with vmPFC lesions showed impaired social emotions [11]. Additionally, deep brain stimulation of the vmPFC region can prolong remission of depression in treatmentresistant patients, indicating a role for this brain region in depressive states $[12,13]$. These human data and our previous findings using chronic psychological stress, which is known to increase vulnerability to the development of depression-like symptoms [14], led us to initially focus on the ILmPFC to better understand the neurobiology of stress and how this might potentially lead to depression sequelae.

To identify as many ILmPFC mechanisms as possible that are involved in the response to repeated stress, we used a genome-wide, gene expression analysis approach. We also chose a restraint stress model as this type of psychological stress affords greater control in application of the stressor than with, for example, the social conflict model. As the neural correlates that underpin the transition to the depressive state are not understood, we tried to identify early stress-induced changes that may increase susceptibility to the development of a full depression-like state. It is known that multiple stress experiences are generally needed to cause MDD in humans and are absolutely required to develop depression-like symptoms in animals, so we used what can be considered a sub-chronic stress paradigm that does not lead to these behavioural symptoms. We found sub-chronic stress resulted in a molecular signature in the ILmPFC, specifically perturbed BDNFNtrk2 (note, Ntrk2 is also known as tyrosine kinase receptor type $B, \operatorname{Trk} B$ ) signalling, that is consistent with known indices of the depressive state and that was prevented with fluoxetine treatment.

\section{Results}

\section{Genome-wide gene expression analysis}

Illumina RatRef-12 Expression BeadChip microarrays and GenomeStudio software were used for genome-wide screening. As gene expression changes are generally subtle in the brain [15], a relatively low fold-change cutoff of 1.2 was used. A statistical significance level of $\mathrm{p} \leq 0.05$ was used after applying a false discovery rate (FDR) to correct for multiple testing [16]. Using these criteria, 263 genes were differentially expressed in the ILmPFC from the stress group compared to controls, with 24 genes having significantly higher expression levels and 239 with significantly lower expression levels (Table 1). The majority of differentially expressed genes showed a fold change of less than 3 , consistent with the notion that brain gene expression changes are generally modest.

\section{Pathways associated with stress-induced gene expression change}

To better interpret the stress-induced changes in gene expression in the ILmPFC with regard to potential biological function, the list of differentially expressed genes was subjected to pathways analysis using the Database for Annotation, Visualisation and Integrated Discovery (DAVID) [17]. DAVID analyzes gene lists to statistically determine whether there is enrichment for genes that belong to a priori defined gene sets. Using the Kyoto Encyclopedia of Genes and Genomes (KEGG) - defined biological pathways, this analysis found enrichment in the list of genes for 8 pathways (Table 2). Notably, neurotrophin signalling was the most significantly enriched pathway in the differentially expressed gene list. Two other pathways associated with neuroplasticity also had relatively high enrichment scores: long-term potentiation (LTP) and erbB signalling. Both of these pathways have been implicated in psychiatric disorders $[7,9]$.

\section{Real-time quantitative PCR (RT-qPCR) confirmation of stress-induced gene changes}

In choosing specific genes for RT-qPCR confirmation, we used one or more of the following criteria: a) presence in enriched gene lists, as determined by DAVID analysis; b) a fold-change in either direction of $\geq 1.2$, as determined by microarray analysis; c) experimental evidence in the literature supporting an involvement for the gene of interest in stress-related mechanisms. For instance, microarray and pathway analyses showed a down-regulation of genes encoding for the neurotrophin receptors Ntrk3 $(-2.28)$ and Ntrk2 $(-1.50)$ and other components of the neurotrophin (or Wnt) signalling pathway such as Camk2a (-1.71), Gsk3ß $(-1.60)$ and Braf (-1.59), in the ILmPFC of rats from the stress group. RT-qPCR analysis confirmed that the expression 
Table 1 Genes identified as differentially expressed by microarray analysis in the IL mPFC of rats submitted to sub-chronic restraint stress when compared to non-stress control ( $p \leq 0.05 ; 1.2$ fold-change cut-off)

\begin{tabular}{|c|c|c|c|c|c|c|c|c|c|}
\hline \multicolumn{8}{|c|}{ Down-regulated genes } & \multicolumn{2}{|c|}{ Up-regulated genes } \\
\hline MAP1B & -2.93 & RGD1565549 & -1.69 & MLLT3 & -1.55 & RGD1306565 & -1.44 & LOC363380 & 1.92 \\
\hline BMPR2 & -2.83 & EEF2K & -1.69 & RGD1561141 & -1.54 & RGD1565486 & -1.44 & LOC360941 & 1.76 \\
\hline LOC497804 & -2.53 & NRP1 & -1.69 & TRIO & -1.53 & RGD1562123 & -1.44 & LOC501221 & 1.68 \\
\hline NTRK3 & -2.28 & $\mathrm{KIF} 5 \mathrm{C}$ & -1.69 & LOC362543 & -1.53 & CPD & -1.44 & ALDH3B1 & 1.68 \\
\hline LOC497765 & -2.24 & LARP5 & -1.68 & LOC497681 & -1.53 & ASAH3L & -1.43 & LOC498374 & 1.62 \\
\hline LOC309928 & -2.13 & RGD1307100 & -1.68 & GRIA3 & -1.53 & NCOA1 & -1.43 & LOC501224 & 1.58 \\
\hline MAP2 & -2.09 & RGD1564560 & -1.68 & LOC360990 & -1.53 & LOC291209 & -1.42 & LOC501093 & 1.55 \\
\hline HELZ & -2.09 & TM9SF4 & -1.68 & GLG1 & -1.53 & ATRN & -1.42 & LOC691487 & 1.54 \\
\hline RICS & -2.08 & DSCAM & -1.68 & RBBP6 & -1.53 & SRRM2 & -1.42 & LOC367381 & 1.49 \\
\hline ZFP537 & -2.04 & PRKCE & -1.68 & LOC500867 & -1.52 & $\mathrm{CDH} 9$ & -1.42 & LOC691672 & 1.47 \\
\hline ODZ4 & -2.00 & RGD1563437 & -1.67 & MYT1L & -1.52 & GPD2 & -1.41 & LOC501223 & 1.45 \\
\hline PCDH17 & -1.95 & USP45 & -1.67 & JMJD1C & -1.52 & LOC362315 & -1.41 & RGD1561850 & 1.45 \\
\hline ODZ3 & -1.95 & RGD1308448 & -1.66 & UNC5C & -1.51 & KPNB1 & -1.41 & GS3 & 1.44 \\
\hline RGD1566031 & -1.95 & RGD1307907 & -1.66 & SPON1 & -1.51 & WDFY1 & -1.41 & CLCC1 & 1.39 \\
\hline RIMS1 & -1.93 & ADD1 & -1.65 & LOC361942 & -1.51 & LOC498048 & -1.41 & LOC690672 & 1.39 \\
\hline ZFPM2 & -1.93 & CALN1 & -1.65 & VPS13D & -1.51 & SIPA1L1 & -1.41 & LOC363434 & 1.39 \\
\hline ODZ3 & -1.91 & RGD1306245 & -1.65 & LOC302405 & -1.51 & RGD1306116 & -1.41 & LOC501245 & 1.39 \\
\hline AFF4 & -1.89 & MTMR9 & -1.65 & LOC363492 & -1.51 & ATF7IP & -1.40 & LOC501089 & 1.39 \\
\hline LOC290704 & -1.89 & MYCL1 & -1.64 & RGD1566279 & -1.50 & NEO1 & -1.40 & LOC501399 & 1.38 \\
\hline APEG3 & -1.88 & KLF7 & -1.64 & LPHN1 & -1.50 & $\mathrm{ABCA} 2$ & -1.40 & RPL7 & 1.37 \\
\hline SGK & -1.85 & RERE & -1.63 & NTRK2 & -1.50 & CD47 & -1.39 & LOC691575 & 1.35 \\
\hline LOC361639 & -1.85 & RIMS2 & -1.62 & RGD1563873 & -1.49 & EHMT1 & -1.39 & LOC363320 & 1.35 \\
\hline ANK2 & -1.84 & TIMP2 & -1.62 & AKAP9 & -1.49 & SLC17A7 & -1.39 & & \\
\hline TNR & -1.83 & SEMA6A & -1.61 & LRP1 & -1.48 & NFIA & -1.38 & & \\
\hline FALZ & -1.82 & KCND2 & -1.61 & LOC500721 & -1.48 & RGS17 & -1.38 & & \\
\hline KCNC2 & -1.80 & LOC497770 & -1.60 & PIM3 & -1.48 & RGD1305534 & -1.38 & & \\
\hline LOC501548 & -1.79 & GSK3B & -1.60 & LUC7L2 & -1.47 & ZFP148 & -1.37 & & \\
\hline CENTG1 & -1.79 & NFIX & -1.60 & LOC497729 & -1.47 & CHD3 & -1.36 & & \\
\hline MDGA2 & -1.78 & GTF2IRD1 & -1.60 & OPCML & -1.46 & LOC497754 & -1.36 & & \\
\hline TMOD2 & -1.76 & PDE10A & -1.59 & NEGR1 & -1.46 & $\mathrm{BPHL}$ & -1.36 & & \\
\hline LOC501637 & -1.76 & BRAF & -1.59 & SLC1A2 & -1.46 & RELN & -1.36 & & \\
\hline CRIM1 & -1.75 & SORL1 & -1.59 & NRIP1 & -1.45 & LOC362587 & -1.35 & & \\
\hline KLF5 & -1.75 & PUM1 & -1.58 & RGD1306101 & -1.45 & FAM108B1 & -1.34 & & \\
\hline C11ORF8H & -1.74 & LCP1 & -1.57 & $\mathrm{MYO5A}$ & -1.45 & USP2 & -1.34 & & \\
\hline SORCS1 & -1.74 & ZFP57 & -1.57 & ZDHHC13 & -1.45 & MAFG & -1.33 & & \\
\hline EDNRB & -1.73 & ARHGAP5 & -1.57 & PPFIA3 & -1.45 & ALCAM & -1.33 & & \\
\hline TOB2 & -1.73 & LOC313658 & -1.57 & ATP2B3 & -1.45 & RGD1307284 & -1.32 & & \\
\hline SLC38A1 & -1.72 & CSPG4 & -1.56 & MAST1 & -1.45 & LOC363849 & -1.32 & & \\
\hline GABRB1 & -1.72 & LOC683578 & -1.56 & USP13 & -1.45 & CAMK2G & -1.32 & & \\
\hline RGD1310722 & -1.72 & KIF5A & -1.56 & LOC367779 & -1.45 & ATP6V0A1 & -1.32 & & \\
\hline PCDH19 & -1.71 & RGD1311049 & -1.56 & RGD1307696 & -1.44 & MPP6 & -1.31 & & \\
\hline CAMK2A & -1.71 & RGD1308329 & -1.56 & CELSR2 & -1.44 & EML2 & -1.31 & & \\
\hline SORCS3 & -1.71 & SYNJ1 & -1.55 & DNAJC5 & -1.44 & LOC501145 & -1.30 & & \\
\hline DUSP8 & -1.70 & KIF1B & -1.55 & EPHA5 & -1.44 & & & & \\
\hline
\end{tabular}


Table 2 Over-represented KEGG pathways in the ILmPFC, 24h post stress according to DAVID

\begin{tabular}{|c|c|c|c|c|c|}
\hline KEGG pathway & pvalue* & $\begin{array}{c}\text { Fold } \\
\text { Enrichment }\end{array}$ & Benjamini & FDR & Genes \\
\hline $\begin{array}{l}\text { Neurotrophin signaling } \\
\text { pathway (04722) }\end{array}$ & $<0.001$ & 6.239 & 0.006 & 0.078 & $\begin{array}{l}\text { BRAF, RGD1306565, CAMK2G, PTPN11, NTRK3, MAP3K5, } \\
\text { GSK3B, NTRK2, PIK3CA, LOC685605, CAMK2A, LOC685653, } \\
\text { LOC685626, LOC685590 }\end{array}$ \\
\hline ErbB signaling pathway (04012) & 0.003 & 6.165 & 0.101 & 2.694 & $\begin{array}{l}\text { CBLB, BRAF, GSK3B, CAMK2G, PIK3CA, LOC685605, } \\
\text { CAMK2A, LOC685626, LOC685653, LOC685590 }\end{array}$ \\
\hline Long-term potentiation (04720) & 0.007 & 6.518 & 0.169 & 6.868 & GRIN2B, BRAF, CAMK2G, GRIN2A, CAMK2A \\
\hline Axon guidance $(04360)$ & 0.014 & 4.126 & 0.252 & 13.797 & EPHA5, SEMA6A, NRP1, PLXNA2, GSK3B, UNC5C \\
\hline Cell adhesion molecules (04514) & 0.025 & 3.541 & 0.346 & 23.766 & GLG1, NCAM1, ALCAM, NLGN2, NEO1, NEGR1 \\
\hline Amyotrophic lateral sclerosis (05014) & 0.028 & 5.922 & 0.332 & 26.567 & SLC1A2, MAP3K5, RGD1306565, GRIN2B, GRIN2A \\
\hline Glioma (05214) & 0.031 & 5.727 & 0.314 & 28.605 & $\begin{array}{l}\text { BRAF, CAMK2G, PIK3CA, LOC685605, CAMK2A, } \\
\text { LOC685626, LOC685653, LOC685590 }\end{array}$ \\
\hline $\begin{array}{l}\text { Phosphatidylinositol signaling } \\
\text { system (04070) }\end{array}$ & 0.044 & 4.991 & 0.375 & 38.162 & $\begin{array}{l}\text { SYNJ1, PIK3CA, LOC685605, LOC497978, LOC685626, } \\
\text { LOC685653, PIP4K2B, LOC685590 }\end{array}$ \\
\hline
\end{tabular}

${ }^{*}=\mathrm{p}<0.05 \mathrm{FDR}=$ false discovery rate.

levels of the genes that encode for Braf, Gsk3 $\beta$, Ntrk2 and Ntrk3 proteins were decreased in the ILmPFC of the stress group, in accordance with microarray results (Figure 1). The decrease in Camk2a gene expression, however, was not confirmed by RT-qPCR. In addition, we probed other genes that were not identified by microarray analysis, but that we considered potentially important. RT-qPCR showed that expression of Mapk1, $m T O R$ and $P i k 3 c b$ genes were all significantly lower in the stressed group compared to controls. The expression level of $A k t 1$ was not significantly altered by stress.

\section{The effects of fluoxetine on ILmPFC stress-induced gene changes}

As we found significant reduction in BDNF signallingrelated genes in the stress group and perturbation in this pathway has been implicated in the aetiology of depression, we determined whether treatment with the antidepressant, fluoxetine, would alter the stress-induced changes in ILmPFC BDNF-related gene expression. As shown in Figure 1, fluoxetine treatment modulated the expression levels of genes involved in the neurotrophin signalling pathway. Fluoxetine significantly reduced the effect of stress on Ntrk2, Gsk3 3 and Pik3cb gene expression in the ILmPFC, such that the levels were not significantly different to home cage controls or fluoxetine treated controls. In contrast, fluoxetine did not alter the effects of stress on the expression of Ntrk3, mTOR, Mapk1, and Braf genes. Fluoxetine administration alone (fluoxetine control animals) also caused a significant decrease in expression levels of Ntrk3 and mTOR when compared to controls without antidepressant or stress (home cage controls). Fluoxetine, and fluoxetine plus stress, caused significant and similar increases in Camk2a mRNA relative to controls and stress.

\section{Discussion}

Stress is a potent risk factor for the development of depression, but the mechanisms that progress the brain's normal response to stress to the pathological state that manifests as depression are poorly understood. Here, we have focussed on the ILmPFC to characterise gene expression changes following repeated, but sub-chronic, episodes of stress. We based our study design on the premise that early neurobiological indices of depression, or at least of the transition into a depression-like state, may be detectable in a sub-chronic model and we chose the PFC because of its known sensitivity to stress and its putative involvement in depression. For instance, stress causes dendritic remodelling in rat IL [18] and other mPFC regions $[19,20]$, synaptic plasticity impairment [21], and deficits in PFC-mediated behaviours [22,23]. Consistent with these preclinical findings, MDD sufferers have reduced neuronal size [24], grey matter volume [25], and activity [26] in the subgenual PFC, the neuroanatomical equivalent of the rodent ILmPFC.

To observe depression-like behavioural and other changes in animals, it is necessary for the animal to experience repeated exposure to the stressor over prolonged periods. For example, in a systematic study of the effects of stress episode duration and number of repeats, Kim and Han demonstrated that at least 14 days of 2 hour daily restraint stress were required to produce significant depression-like behaviours [27]. Consistent with this finding, McLaughlin and co-workers found restraint stress of 6 hours per day for 21 days was required to induce morphological and functional changes in another brain region affected in depression, the hippocampus [28]. In a social interaction model, at least 10 consecutive days of social defeat appear necessary for depression-like symptomology to appear, at least in a subset of "susceptible" animals [14,29-31]. Similarly, multiple repeats of 
A

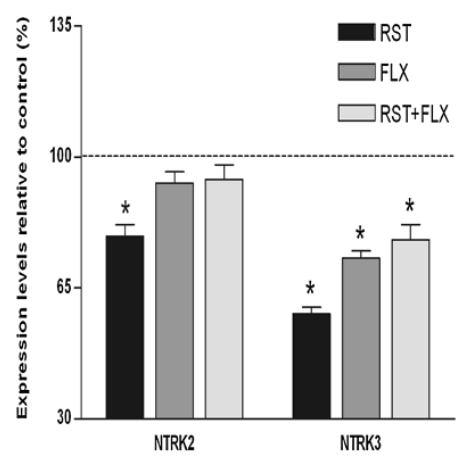

C

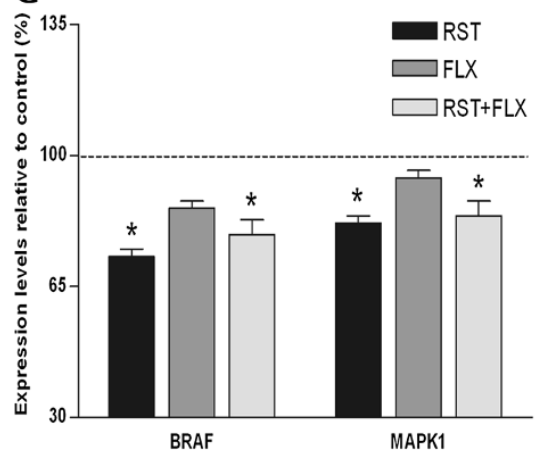

B
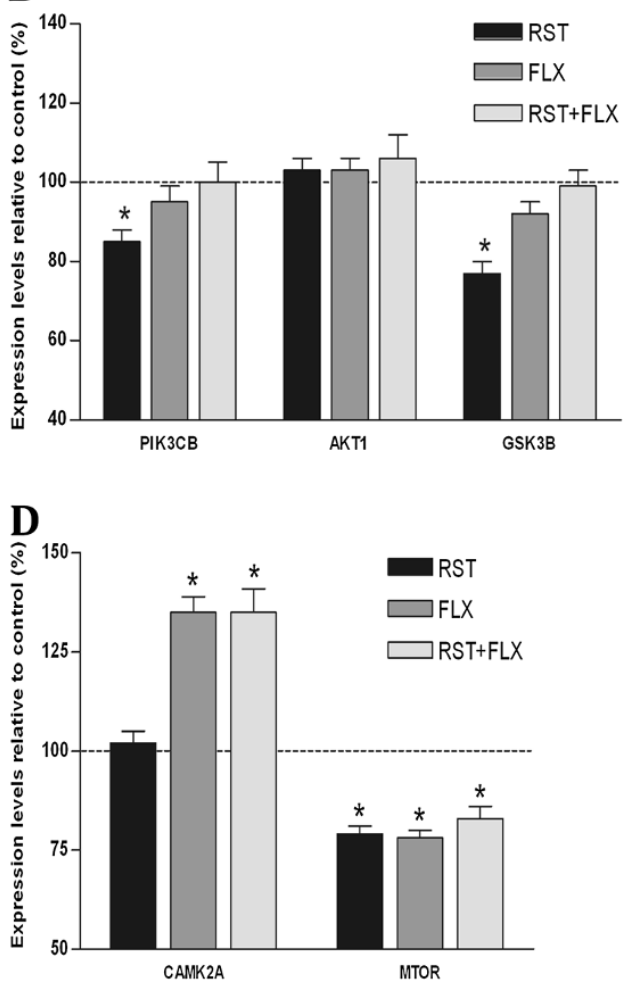

Figure 1 A-D Graphs depicting the effects of sub-chronic restraint stress (RST), fluoxetine treatment without stress (FLX), and fluoxetine treatment with stress (RST+FLX) on gene expression in the ILmPFC. Values are percentage means ( \pm SEM) relative to unhandled controls (dashed horizontal line at 100\%). Sub-chronic restraint stress reduced the transcript levels for the plasma membrane neurotrophin receptor genes ntrk2 and ntrk3 (A). Note, chronic fluoxetine treatment prevented the stress-induced ntrk2 but not ntrk3 transcript reduction. Sub-chronic restraint stress reduced transcript levels for the PI3K-AKT1-GSK3B (B) and NTRK2-MAPK/ERK (C) but not the PLCY1 (D) intracellular signalling pathways. Interestingly, fluoxetine treatment prevented the sub-chronic stress-induced reduction in PI3K-AKT1-GSK3B signalling pathway, but not the NTRK2-MAPKJERK (B-Raf and MAPK1 genes) pathway. Gene expression of the serine-threonine kinase, mTOR, a downstream target of the PI3K-AKT1 pathway, was reduced by sub-chronic stress, an effect not prevented by fluoxetine (D). ${ }^{*}$ denotes $p<0.05$.

stress episodes are also necessary in the chronic mild stress model of depression [32]. It should be noted that single episodes of stress can elicit behavioural changes, however, these are considered characteristic of anxiety per se, rather than depression [33,34]. With respect to anxiety, we cannot completely discount the possibility that our sub-chronic stress-induced molecular changes are also related to anxiety. The link between stress and anxiety is well-established and there is considerable overlap in the putative mechanisms and behaviours between anxiety and depression. Furthermore, some antidepressants also have anxiolytic properties. Regarding this possibility, there is conflicting evidence in the literature. It is known that a single restraint episode, for example, can result in the delayed appearance of anxiety-like behaviour [35], and Kim and Han (2006) demonstrated that animals subjected to a more chronic restraint stress paradigm (6h/day for 10 consecutive days) did not display anxiety related behaviours as assessed with the elevated plus maze [27]. One explanation is that acute stress episodes are more likely to induce anxiety like behaviours and as the stress becomes more chronic there is a transition to a more depression-like behavioural phenotype. However, others have shown that anxiety-like behaviours can be displayed, in addition to depression-like ones, after many weeks of chronic restraint stress [36]. Clearly, more work needs to be done to understand the relationship between the nature of stress (type, intensity, duration, frequency) and the development of anxiety and depression. A potential limitation of the present study concerns the lack of a single acute stress group for comparison with the control and sub-chronic groups. Notionally, this type of acute stressor might have caused a similar molecular profile. However, we consider this possibility to be extremely unlikely given that Bland et al. (2007) used a single 80 minute session of electric shock, a stressor that is far more intense than our restraint stress, and found the stressed induced changes in neurotrophin transcripts in all regions of the $\mathrm{MPFC}$, including ILmPFC, had returned to baseline by 24 hours post-stress [37]. 
To identify stress-related mechanisms that may potentially lead to the development of pathology, we first carried out a genome-wide gene expression analysis using moderately stringent criteria to define differentially expressed genes. A number of previous studies have also taken this approach [38], but direct gene-by-gene comparisons with these studies is problematic due to the different stress paradigms and microarray platforms used, as well as variation in brain region taken for analysis. Indeed, Surget and colleagues showed remarkably little overlap (zero genes for 3-region overlap) in gene expression between the cingulate cortex, amygdala and dentate gyrus of chronically stressed animals [39]. With regard the pattern of gene expression, we found the vast majority of differentially expressed genes were down-regulated, with most of the up-regulated transcripts being predicted genes or pseudogenes. Down regulation of a majority of genes in the PFC has also been observed following chronic stress $[40,41]$. To improve interpretability of the microarray data in relation to gene function in biological processes, we carried out pathway analysis whereby the degree to which sets of genes belonging to a priori determined biological pathways were enriched in the differentially expressed gene list was assessed using DAVID $[17,42,43]$. We identified eight significantly enriched pathways (Table 2), three had FDRs less than 10\% and we focussed on these. Notably, all three of these pathways have been implicated in neuropsychiatric disorders $[7,9]$.

The most significantly enriched pathway, and the one with the lowest FDR, was for neurotrophin signalling. There is a substantial body of evidence implicating BDNF in MDD. For example, BDNF and Ntrk2 transcripts and protein levels were markedly reduced in the PFC and amygdala of MDD subjects [44,45]. Also, serum BDNF is lower in MDD sufferers [46] and BDNF is being considered a predictive diagnostic marker for MDD [47]. Additionally, a number of chronic stress-based animal models of MDD have shown perturbation in the BDNFNtrk2 signalling pathway in various brain regions [48-50]. Indeed, Nestler and colleagues have demonstrated a crucial role for BDNF in the mesolimbic system for the development of depression-like behaviour [14,29]. We did not find stress-induced change in BDNF transcript levels in ILmPFC, which may imply that BDNF protein levels are also unchanged. This raises the question as to why Ntrk2 levels should change if BDNF does not. One possibility is that BDNF protein is delivered by dopaminergic afferents $[14,29,51]$ to the ILmPFC and, consistent with this notion, we have found increased BDNF transcript levels in VTA dopamine neurons (manuscript in preparation). Alteration in the BDNF pathway can also be observed in some acute stress models, however as mentioned above, these changes are typically short-lived [37,52-55]. Our altered BDNF-Ntrk2 pathway finding was evident at 24 hours post the last stress episode of the sub-chronic stress paradigm and is consistent with a molecular signature of depression. The sub-chronic stress paradigm used in the present study does not induce depression-like behaviours, therefore, this molecular finding may represent an early mechanistic indicator of depression neuropathology. Prevention of the subchronic stress-induced BDNF-Ntrk2 perturbation by the antidepressant, fluoxetine, is consistent with this notion. Furthermore, it may also indicate that the ILmPFC is a particularly sensitive region to stress and therefore important in the development of the depressive state.

BDNF (or NT3/4) binding to Ntrk2 can activate three main intracellular signalling cascades: mitogen-associated protein kinase (MAPK; also known as the Ras/ERKMAPK pathway), phosphotidylinositol-3 kinase (PI3K) Akt, and the phospholipase C- $\gamma 1$ (PLC 1 1) cascades $[56,57]$. As Ntrk2 is the post-synaptic entry point to the BDNF/Ntrk2 signalling cascade, reduced ntrk2 levels might be expected to affect each of these intracellular signalling cascades and have significant impact on diverse cell functions. Indeed, genetically reduced BDNF/Ntrk2 levels result in altered activity-dependent synaptogenesis [58], synaptic function, such as LTP [59,60], learning [59] and, importantly, stress-related behaviours [61]. Our RTqPCR data indicate that sub-chronic stress induced reduction in Ntrk2 transcript levels may in fact not impact each of these signalling pathways. For example, both the PI3K-Akt (PIK3CB and GSK3B genes) and MAPK/ERK (B-Raf and MAPK1 genes) pathways were affected by sub-chronic stress, but the PLC $\gamma 1$ (CAMK2A gene) was spared. One important downstream target of the PI3KAkt and MAPK/ERK pathways is the mammalian target of rapamycin (mTOR), a kinase involved in many cellular processes [62], including translation of synaptic proteins that underpin plasticity [63], and, therefore, potentially important in the development of the depressive state [9]. Although mTOR was not identified as being differentially expressed by microarray, using RT-qPCR we found it to be significantly reduced, consistent with changes in the aforementioned upstream regulatory pathways. This is supportive for a potential role in maladaptive neuronal plasticity contributing to the depressive state, although this will obviously require further experimental elucidation, particularly at the protein level.

Interestingly, antidepressant treatment with fluoxetine only prevented the sub-chronic stress-induced changes in the PI3K-Akt pathway related transcripts (PIK3CB and GSK3B genes), with B-RAF and MAPK1 gene transcripts of the MAPK/ERK pathway not significantly different to the stress without fluoxetine levels. This may indicate that the effects of fluoxetine antidepressant treatment are preferentially mediated by the PI3K-Akt pathway, at least in this brain region, and suggest that 
targeting components of this pathway may be of future therapeutic interest. In this regard it is notable that GSK3B has been implicated in the pathophysiology of mood disorders $[8,64]$. For example, GSK3B is one target for the mood-stabilising drug lithium, it is also required for the antidepressant effects of ketamine [65], and in MDD sufferers, GSK3B kinase activity is increased in the PFC [66]. Consistent with a role for GSK3B in depression, fluoxetine increases phosphorylation of GSK3B at a specific N-terminal serine residue, thereby decreasing the kinase's activity [67]. Conversely, increasing GSK3B activity through viral-mediated overexpression, induces a depression-like phenotype in an animal model [68]. How a reduction in GSK3B at the transcript level, as seen in the present study, fits into this scheme is not clear. Interestingly though, and consistent with our data, GSK3B gene expression but not protein levels, was reduced in the nucleus accumbens of depressionsusceptible animals in a chronic social defeat model of depression [68]. This similarity between our GSK3B finding and that of Wilkinson et al., 2011 [68], further supports our contention that we are seeing an early molecular signature of depression in the sub-chronic stress model. It should also be noted that GSK3B is not limited to the BDNF/Ntrk2 pathway as it is an important component of the Wnt-Frizzled signalling cascade, as well as being a downstream target of PKA, PKC and Akt [69], all of which are components of multiple signalling cascades. The Wnt-Frizzled signalling pathway has recently been implicated in depression $[68,70]$.

We also found sub-chronic stress reduced ILmPFC transcript levels for Ntrk3, the cognate receptor for the neurotrophin, NT-3. Like BDNF, NT-3 has also been implicated in MDD. For instance, NT-3 gene expression was reduced in peripheral blood cells of individuals during depressive but not remissive states [71] and Ntrk3 transcript and protein levels were reduced in some brain regions of MDD patients [72] as were NT-3 levels [73]. Surprisingly, we found fluoxetine alone also reduced the expression of Ntrk3. Previously, it was shown that SSRI treatment had no effect on CSF NT-3 protein levels in MDD [74] and transcript levels in rat hippocampus [75]. The Ntrk3 transcript reduction seen in the present study may reflect a similar mechanism to that causing Ntrk2 reduction. Why this particular receptor was affected by fluoxetine remains to be determined.

\section{Conclusions}

To further elucidate potential neurobiological mechanisms that may increase depression susceptibility, we have used a sub-chronic stress paradigm that is not capable of inducing behaviours that are characteristic of depression, and evaluated the infralimbic prefrontal cortex for molecular indices that may constitute an early signature for this psychopathology. We found that the BDNF-Ntrk2 pathway was affected by the stress paradigm as was GSK3B, which is a component of both the neurotrophin as well as the Wnt signalling cascades. Both the Ntrk2 and Wnt signalling pathways are implicated in depression and, consistent with the notion that our molecular findings represent early depression neuropathology, the stress-induced perturbations in these pathways were prevented by pretreatment with an antidepressant, fluoxetine, a selective serotonin reuptake inhibitor. These findings indicate that brain signalling pathways that are known to be abnormal in fully developed depressive states are actually perturbed well before the manifestation of behaviours that characterise depression.

\section{Methods}

\section{Animals}

Adult, male, Sprague-Dawley rats (20-22 weeks of age) were used for all experiments. Animals were obtained from the Animal Services Unit at the University of Newcastle, group-housed (4 per cage) on arrival and maintained in a temperature $\left(21^{\circ} \mathrm{C} \pm 1\right)$ and humidity controlled environment with food and water available ad libitum. Lighting was set for a 12:12 hour reverse lightdark cycle (lights off at 7:00AM; lights on at 7:00PM). All procedures were conducted in the dark phase. Animal housing and procedures were carried out in strict accordance with the University of Newcastle's Animal Care and Ethics Committee regulations, the NSW Animal Research Act and Regulations, and the Australian Code of Practice for the care and use of animals for scientific purposes.

\section{Experimental procedures}

Stress treatment: After a minimum of one week for acclimatisation, rats were randomly assigned to experimental groups ( $n=6$ per group) and housed 2 per cage. The control group consisted of animals that were maintained, without handling, under normal housing conditions until the day of sacrifice. We kept our control group as stressnaïve as possible in order to improve the probability of detecting subtle stress-related changes in the brain. It is known that handling alone is stressful to animals, although in the context of handling related stress and the mPFC, it has been shown that 7 days of handling rats for restraint stress did not alter mPFC pyramidal neuron dendrite morphology [20]. Animals in the stress group were subjected to a sub-chronic stress regimen that consisted of the handling necessary for and the daily sessions of 1 hour restraint in a Plexiglas tube $(7.5 \times 18 \mathrm{~cm})$, for 5 consecutive days. There are many stress paradigms that can be used in pre-clinical studies of depression, however, they all suffer various limitations and there is no consensus as to which is the optimal one [76]. Restraint stress is 
a pain-free, physical stressor that elicits a stress response that is, in part, psychogenic, and one advantage of this stress method is the ability to readily control stressor parameters (intensity, duration, frequency), although, as with all stress paradigms, the individual animal's stress response is not controllable. Importantly, we and others have shown chronic restraint stress can induce depression-like behaviours (e.g. anhedonia) and synaptic changes thought to contribute to these behaviours (e.g. dendritic retraction and impaired synaptic plasticity) $[21,23,27]$. Furthermore, the antidepressant fluoxetine has been shown to prevent development of depression-like behaviours following chronic restraint stress [77]. Taken together, these findings indicate the restraint stress model has a certain degree of construct, face and predictive validity [76] and is suitable for a sub-chronic exposure paradigm. The stress protocol was initiated at 10 a.m. each day and animals were returned to their pair-housed cage condition immediately after session completion. Animals were killed by an overdose of pentobarbitone (Lethabarb ${ }^{\circledR}$ ) $24 \mathrm{~h}$ after the last stress session. Food and water were available ad libitum in home cages.

Chronic fluoxetine treatment: Selective serotonin reuptake inhibitors (SSRIs) have been an important class of drugs for the treatment of depression ever since the introduction of fluoxetine, the original member of this class approved to treat humans. Much debate continues regarding the relative efficacies within and between the various classes of antidepressants, not to mention the specific molecular targets, intended and non-intended, of the antidepressants. Suffice to say, long-term treatment with SSRIs like fluoxetine, has been shown to significantly reduce the risk of relapse of depression [78] and, importantly, in the context of the present study, fluoxetine can prevent chronic stress induced brain BDNF deficits [50]. To assess the effect of fluoxetine antidepressant on ILmPFC gene expression following subchronic stress, a second batch of rats was randomly assigned into 2 groups ( $n=6$ per group) and in order to avoid injection stress, fluoxetine was administered via drinking water for 21 days prior to the start of the subchronic stress protocol. Rats were pair-housed to avoid social isolation stress. To deliver a target dose of approximately $10 \mathrm{mg} / \mathrm{Kg} /$ day of fluoxetine hydrochloride ((7)-N-methyl-g-(4-[trifluoromethyl]-phenoxy)-benzenepropanamine), the average daily water intake was measured over a period of 4 days and the appropriate concentration of the drug then calculated to be delivered in that volume. Administration of fluoxetine at this dose, via drinking water to group-housed animals (up to 7 rats per cage), has been shown to be efficacious $[79,80]$ and we have previously found this method results in a plasma fluoxetine concentration of $267 \pm 50 \mathrm{ng} / \mathrm{ml}$ (mean \pm SEM; unpublished data). Body weight and drug solution intake were recorded daily throughout the period of fluoxetine administration. Fluoxetine treatment was maintained throughout the stress regimen until rats were killed at the end of the experiment. The fluoxetine control group received the same drug treatment but animals were maintained, without handling, under normal housing conditions until the day of sacrifice. Both groups had access only to fluoxetine-treated water for the duration of the experiment. Food was available ad libitum.

\section{Tissue preparation and RNA extraction}

After decapitation and craniotomy, the brain was rapidly removed and cooled in ice-cold diethyl pyrocarbonate (DEPC)-treated PBS. Brains were then placed in an icecold metal brain matrix and the frontal lobe separated in the coronal plane and instantly frozen in dry-ice chilled isopentane. Tissue was stored at $-80^{\circ} \mathrm{C}$ until needed. A series of $500 \mu \mathrm{m}$-thick coronal cryosections were obtained through the rostrocaudal extent of the ILmPFC $(+2.5$ to $+4.0 \mathrm{~mm}$ relative to Bregma) [81]. Sections were then placed onto chilled RNAse-free glass microscope slides and the ILmPFC bilaterally excised using a 0.8 $\mathrm{mm}$ diameter stainless steel punch. ILmPFC tissue punches were obtained from three brain sections, pooled and homogenized with a motorized pestle in a RNAsefree microtube containing $350 \mu \mathrm{l}$ of RNA lysis buffer (Qiagen). Homogenised samples were stored at $-80^{\circ} \mathrm{C}$ until needed. Total RNA was then extracted and contaminating genomic DNA (gDNA) removed by insolution DNase digestion followed by RNA Cleanup. RNA extraction, clean up and DNA digestion were done using RNeasy ${ }^{\circledR}$ Micro Kit and DNase reagents (Qiagen) according to manufacturer's instructions. RNA yield and purity were estimated by absorbance spectrophotometry (NanoDrop 1000; Thermo Scientific). RNA integrity was evaluated by qPCR comparison of the relative levels of the $3^{\prime}$ and $5^{\prime}$ ends of the transcripts for the housekeeping genes glyceraldehyde-3-phosphate dehydrogenase (GAPDH) and $\beta$-actin (primers are listed in Table 3), as previously described [82]. RNA samples were further processed for either microarray hybridization or real-time, quantitative polymerase chain reaction (RT-qPCR).

\section{Gene expression microarray data processing}

Microarrays were processed by the Australian Genomics Research Facility (AGRF; Melbourne, Australia). 100ng of total RNA, obtained from the ILmPFC was used for microarray analysis. For microarray analysis we used RNA from 4 of the 6 animals in each group, whereas for qPCR, RNA from each of the 6 animals was used. RNA quality was first checked using an Agilent Bionalyser, and then prepared for hybridization onto Illumina RatRef-12 Expression BeadChips. Arrays were scanned 
Table 3 Primers used for validation of stress-responsive genes by RT-qPCR

\begin{tabular}{|c|c|c|c|c|}
\hline Gene ID & Symbol & Sense $\left(5^{\prime}-3^{\prime}\right)$ & Antisense $\left(5^{\prime}-3^{\prime}\right)$ & $\begin{array}{c}\text { Amplicon } \\
\text { size (bp) } \\
\end{array}$ \\
\hline $18 \mathrm{~S}$ ribosomal RNA & Rn18s & CCCGAAGCGTTTACTTTGAA & СССТCTTAATCATGGCCTCA & 136 \\
\hline Glyceraldehyde-3-phosphate dehydrogenase & Gapdh & GAAGGGCTCATGACCACAGT & GGATGCAGGGATGATGTTCT & 117 \\
\hline Actin, beta & $A c t b$ & CACACTGTGCCCATCTATGA & CCGATCGTGATGACCTGACC & 272 \\
\hline $\begin{array}{l}\text { Calcium/calmodulin-dependent protein } \\
\text { kinase II alpha }\end{array}$ & Camk2a & GCCTGGACTTTCATCGATTC & GGTACTGAGTGATGCGGATGT & 141 \\
\hline Glycogen synthase kinase 3 beta & Gsk3 $\beta$ & GCGAGACACACCTGCCCTCTTC & GTGGCCAGAGGTGGGTTACTTGAC & 66 \\
\hline $\begin{array}{l}\text { Mammalian target of rapamycin } \\
\text { (serine/threonine kinase) }\end{array}$ & mTOR & TTGGATGTTCCAACCCAAGT & CAGGCCTTGGTTACCAGAAA & 106 \\
\hline Neurotrophic tyrosine kinase, receptor, type 2 & Ntrk2 & TGGAGGGCGACCCACTCATCA & TCAGCTCGG TGGGCGGGTTA & 123 \\
\hline Neurotrophic tyrosine kinase, receptor, type 3 & Ntrk3 & CATCCGCTGGATGCCACCTGAAA & AAGACACGGCCTTGGGTGATGCA & 50 \\
\hline Phosphoinositide-3-kinase, catalytic, beta polypeptide & Pik3cb & CCTGCGACAGATGAGTGATG & CAATCCTCCGGTTGTCAAGT & 134 \\
\hline V-raf murine sarcoma viral oncogene homolog B1 & Braf & CATGGCGACGTGGCAGTGAAAATG & TGAGGTGTGGGTGCTGTCACATTC & 50 \\
\hline Glyceraldehyde-3-phosphate dehydrogenase-3-prime & Gapdh-3' & GGCTGGCATTGCTCTCAA & GAGGTCCACCACCCTGTTG & 88 \\
\hline Glyceraldehyde-3-phosphate dehydrogenase-5-prime & Gapdh-5' & GACAGCCGCATCTTCTTG & CACCGACCTTCACCATCTTG & 63 \\
\hline Actin, beta-3-prime & Actb-3' & CCTAGCACCATGAAGATCAAGA & GCCAGGATAGAGCCACCAATC & 77 \\
\hline Actin, beta-5-prime & Actb- $5^{\prime}$ & ACCCAGATCATGTTTGAGACCTT & CAGAGGCATACAGGGACAAC & 79 \\
\hline
\end{tabular}

using standard Illumina protocols. RatRef-12 Expression microarrays probe for 21,910 genes. Raw intensity data was then imported into Illumina GenomeStudio Data Analysis Software and statistical analysis of gene expression was carried out using the Gene Expression module (version 1.1.1). First, a background measure based on the average signal of negative control probes was obtained and subtracted from all probes of the array. Next, the data was normalized by the GenomeStudio Average Normalization algorithm to adjust sample signals and minimize variation arising from non-biological factors. The p-values for differential expression were then calculated using the Illumina Custom Error Model algorithm and the Benjamini and Hochberg false discovery rate (FDR), a multiple testing correction method for adjustment of p-values [16]. Genes were considered to be differentially expressed if the comparison resulted in a $\mathrm{p}$-value $\leq 0.05$ and $\mathrm{a} \geq 1.2$ fold-change in expression (in either direction).

\section{Real-time quantitative polymerase chain reaction (RT-qPCR)}

For confirmation of gene expression changes, RT-qPCR was carried out on mRNA from all 6 animals of each group. Gene-specific primer pairs (Table 3) were designed with the web-based NCBI primer-BLAST software (http://www.ncbi.nlm.nih.gov/tools/primer-blast/), and targeted sequence near the $3^{\prime}$ end of the cDNA and, where possible, amplicons spanned intron:exon boundaries. cDNA was generated by reverse transcription using SuperScript III (Invitrogen) according to manufacturer's instructions. Briefly, 200ng of total RNA, $1 \mu \mathrm{l}$ of $50 \mu \mathrm{M}$ ) oligo $(\mathrm{dT})_{20}$ primer, $0.5 \mu \mathrm{l}$ of $20 \mu \mathrm{M} 18 \mathrm{~S}$ RNA-specific primer ( $5^{\prime}$-GAACTACGACGGTATCTGA-3'), $1 \mu \mathrm{l}$ of $10 \mathrm{mM}$ $\mathrm{dNTP}$, and molecular biology grade water to $13 \mu \mathrm{l}$, were mixed and heated for 5 minutes at $65^{\circ} \mathrm{C}$, then chilled on ice for 1 minute. $4 \mu \mathrm{l} 5 \mathrm{X}$ First-Strand Buffer, $1 \mu \mathrm{l}$ of $0.1 \mathrm{M}$ DTT, $1 \mu \mathrm{l}$ RNaseOUT (40 units/ $\mu \mathrm{l}$ ) and $1 \mu \mathrm{l}$ SuperScript III RT (200 units/ $\mu \mathrm{l}$ ) were added and the mixture incubated for 60 minutes at $50^{\circ} \mathrm{C}$, followed by 15 minutes at $70^{\circ} \mathrm{C}$. Reverse transcription reactions without reverse transcriptase were also done to assess gDNA contamination. qPCR reactions were carried out in $12 \mu$ l volumes

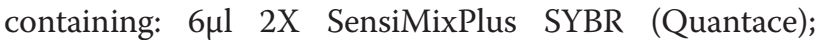
200nM each of forward and reverse primers, except for $18 \mathrm{~S}$ rRNA, where $1 \mu \mathrm{M}$ was used; 1ng cDNA; molecular biology grade water to $12 \mu \mathrm{l}$. After an initial 10 minute, $95^{\circ} \mathrm{C}$ enzyme activation step, 40 cycles of $95^{\circ} \mathrm{C}$ for $30 \mathrm{sec}$ (step 1) followed by $60^{\circ} \mathrm{C}$ for 31 sec (step 2) were completed. Only primers that produced a single amplified product as shown by melt curve and gel electrophoresis analyses were used. Reactions were carried out on an ABI 7500 Real-Time PCR System (Applied Biosystems) and analyzed using the Applied Biosystems 7500 Sequence Detection Software (Version 1.4). Relative expression levels were determined using the comparative Ct method ( $\Delta \Delta \mathrm{Ct}$; [83], where gene expression was first normalised to the average of $18 \mathrm{~S}$ rRNA, GAPDH and $\beta$-actin, to generate a $\Delta \mathrm{Ct}$ for each gene and sample, and then the average $\Delta \mathrm{Cts}$ for each gene were compared between the various groups. Statistical analysis of relative gene expression was done by comparisons between 
groups using Student's t tests with Bonferroni correction to the alpha level to control for family-wise error.

\section{Pathway analysis}

Pathway analysis of differentially expressed genes was undertaken using the Database for Annotation, Visualization, and Integrated Discovery bioinformatics resource (DAVID; http://david.abcc.ncifcrf.gov/; [17]. DAVID is a gene-centered database that integrates gene annotation resources and facilitates high-throughput gene functional analysis by conferring biological meaning to a gene. Enrichment analysis was performed in the "Pathway" annotation category primarily using the Kyoto Encyclopedia of Genes and Genomes (KEGG) pathway database for annotated terms. All other analysis parameters were left as the default. For a detailed description of the algorithms and statistical parameters used by DAVID for enrichment results see [42].

\section{Abbreviations}

ILmPFC: Infralimbic medial prefrontal cortex; BDNF: Brain-derived neurotrophic factor; ntrk2: Neurotrophin receptor tyrosine kinase 2; MDD: Major depressive disorder; vmPFC: Ventromedial PFC; FDR: False discovery rate; DAVID: Database for annotation, visualisation, and integrated discovery; KEGG: Kyoto encyclopedia of genes and genomes; LTP: Long-term potentiation; RT-qPCR: Real-time quantitative PCR; mRNA: Messenger RNA; MAPK: Mitogen-associated protein kinase; PI3K: Phosphotidylinositol-3 kinase; PLCY1: Phospholipase C- $\gamma$ 1; mTOR: Mammalian target of rapamycin; GSK3B: Glycogen synthase kinase 3B; PKA: Protein kinase A; PKC: Protein kinase C; Akt: Also known as protein kinase B (PKB); DEPC: Diethyl pyrocarbonate; RNA: Ribonucleic acid; gDNA: Genomic DNA; GAPDH: Glyceraldehyde-3-phosphate dehydrogenase; AGRF: Australian genomics research facility; cDNA: Complementary DNA; dNTP: Deoxy nucleotide triphosphate; DTT: Dithiothreitol.

\section{Competing interests}

The authors declare they have no competing interests.

\section{Authors' contributions}

RB carried out all the experimental work, performed the pathways and $\mathrm{PPCR}$ statistical analyses, prepared all figures and tables and assisted with the writing of the manuscript. FRW contributed to the conceptual design of the study and assisted with critical revisions of the manuscript. PRD and TAD contributed to data interpretation and critical revisions of the manuscript. DWS was responsible for overall design and execution of the study, analysis and interpretation of the data and writing of the manuscript. All authors read and approved the final manuscript.

\section{Acknowledgements}

This work was supported by the National Health and Medical Research Council of Australia, the Hunter Medical Research Institute, and the Priority Research Centre for Translational Neuroscience and Mental Health at the University of Newcastle. We would like to thank Dr Chris Dayas for his input on the manuscript.

\section{Author details}

${ }^{1}$ School of Biomedical Sciences and Pharmacy Faculty of Health, University of Newcastle, Callaghan, NSW 2308, Australia. ${ }^{2}$ Priority Research Centre for Translational Neuroscience and Mental Health, University of Newcastle, Callaghan, NSW 2308, Australia. ${ }^{3}$ Hunter Medical Research Institute, John Hunter Hospital, New Lambton Heights, NSW 2310, Australia. ${ }^{4}$ Present Address Faculty of Science and Technology, Deacon University, Geelong, VIC 3220, Australia.

Received: 1 April 2012 Accepted: 15 October 2012

Published: 18 October 2012

\section{References}

1. Hammen C: Stress and depression. Annu Rev Clin Psychol 2005, 1:293-319.

2. Mazure C: Life stressors as risk factors in depression. Clin Psychol Sci Prac 1998, 5:291-313.

3. Ulrich-Lai YM, Herman JP: Neural regulation of endocrine and autonomic stress responses. Nat Rev Neurosci 2009, 10(6):397-409.

4. Christoffel DJ, Golden SA, Russo SJ: Structural and synaptic plasticity in stress-related disorders. Rev Neurosci 2011, 22(5):535-549.

5. Popoli M, Yan Z, McEwen BS, Sanacora G: The stressed synapse: the impact of stress and glucocorticoids on glutamate transmission. Nat Rev Neurosci 2012, 13(January):22-37.

6. Sousa N, Cerqueira JJ, Almeida OF: Corticosteroid receptors and neuroplasticity. Brain Res Rev 2008, 57(2):561-570.

7. Castren E, Rantamaki T: The role of BDNF and its receptors in depression and antidepressant drug action: Reactivation of developmental plasticity. Dev Neurobiol 2010, 70(5):289-297.

8. Duman RS, Voleti B: Signaling pathways underlying the pathophysiology and treatment of depression: novel mechanisms for rapid-acting agents. Trends Neurosci 2012, 35(1):47-56.

9. Pittenger C, Duman RS: Stress, depression, and neuroplasticity: a convergence of mechanisms. Neuropsychopharmacology 2008, 33(1):88-109.

10. Hinwood M, Tynan RJ, Day TA, Walker FR: Repeated social defeat selectively increases deltaFosB expression and histone $\mathrm{H} 3$ acetylation in the infralimbic medial prefrontal cortex. Cereb Cortex 2011 21(2):262-271.

11. Koenigs M, Young L, Adolphs R, Tranel D, Cushman F, Hauser M, Damasio A: Damage to the prefrontal cortex increases utilitarian moral judgements. Nature 2007, 446(7138):908-911.

12. Mayberg HS, Lozano AM, Voon V, McNeely HE, Seminowicz D, Hamani C, Schwalb JM, Kennedy SH: Deep brain stimulation for treatment-resistant depression. Neuron 2005, 45(5):651-660.

13. Kennedy SH, Giacobbe P, Rizvi SJ, Placenza FM, Nishikawa Y, Mayberg HS, Lozano AM: Deep brain stimulation for treatment-resistant depression: follow-up after 3 to 6 years. Am J Psychiatry 2011, 168(5):502-510.

14. Krishnan V, Han MH, Graham DL, Berton O, Renthal W, Russo SJ, Laplant Q, Graham A, Lutter M, Lagace DC, et al: Molecular adaptations underlying susceptibility and resistance to social defeat in brain reward regions. Cell 2007, 131(2):391-404.

15. Mirnics K, Pevsner J: Progress in the use of microarray technology to study the neurobiology of disease. Nat Neurosci 2004, 7(5):434-439.

16. Benjamini $Y$, Hochberg Y: Controlling the false discovery rate: a practical and powerful approach to multiple testing. J Royal Statistical Soc 1995, 57(1):289-300.

17. Dennis G Jr, Sherman BT, Hosack DA, Yang J, Gao W, Lane HC, Lempicki RA: DAVID: database for annotation, visualization, and integrated discovery. Genome Biol 2003, 4(5):P3.

18. Shansky RM, Hamo C, Hof PR, McEwen BS, Morrison JH: Stress-induced dendritic remodeling in the prefrontal cortex is circuit specific. Cereb Cortex 2009, 19(10):2479-2484.

19. Radley JJ, Rocher AB, Rodriguez A, Ehlenberger DB, Dammann M, McEwen BS, Morrison JH, Wearne SL, Hof PR: Repeated stress alters dendritic spine morphology in the rat medial prefrontal cortex. J Comp Neurol 2008, 507(1):1141-1150.

20. Brown SM, Henning S, Wellman CL: Mild, short-term stress alters dendritic morphology in rat medial prefrontal cortex. Cereb Cortex 2005, 15(11):1714-1722

21. Goldwater DS, Pavlides C, Hunter RG, Bloss EB, Hof PR, McEwen BS, Morrison JH: Structural and functional alterations to rat medial prefrontal cortex following chronic restraint stress and recovery. Neuroscience 2009, 164(2):798-808.

22. Liston C, Miller MM, Goldwater DS, Radley JJ, Rocher AB, Hof PR, Morrison JH, McEwen BS: Stress-induced alterations in prefrontal cortical dendritic morphology predict selective impairments in perceptual attentional set-shifting. J Neurosci 2006, 26(30):7870-7874.

23. Hinwood M, Morandini J, Day TA, Walker FR: Evidence that microglia mediate the neurobiological effects of chronic psychological stress on the medial prefrontal cortex. Cereb Cortex 2012, 22(6):1442-1454.

24. Chana G, Landau S, Beasley C, Everall IP, Cotter D: Two-dimensional assessment of cytoarchitecture in the anterior cingulate cortex in major depressive disorder, bipolar disorder, and schizophrenia: evidence for 
decreased neuronal somal size and increased neuronal density. Biol Psychiatry 2003, 53(12):1086-1098.

25. Frodl TS, Koutsouleris N, Bottlender R, Born C, Jager M, Scupin I, Reiser M, Moller HJ, Meisenzahl EM: Depression-related variation in brain morphology over 3 years: effects of stress? Arch Gen Psychiatry 2008, 65(10):1156-1165.

26. Drevets WC, Price JL, Simpson JR Jr, Todd RD, Reich T, Vannier M, Raichle ME: Subgenual prefrontal cortex abnormalities in mood disorders. Nature 1997, 386(6627):824-827.

27. Kim KS, Han PL: Optimization of chronic stress paradigms using anxiety- and depression-like behavioral parameters. J Neurosci Res 2006, 83(3):497-507.

28. McLaughlin KJ, Gomez JL, Baran SE, Conrad CD: The effects of chronic stress on hippocampal morphology and function: an evaluation of chronic restraint paradigms. Brain Res 2007, 1161:56-64.

29. Berton O, McClung CA, Dileone RJ, Krishnan V, Renthal W, Russo SJ, Graham D, Tsankova NM, Bolanos CA, Rios M, et al: Essential role of BDNF in the mesolimbic dopamine pathway in social defeat stress. Science 2006, 311(5762):864-868.

30. Tsankova NM, Berton O, Renthal W, Kumar A, Neve RL, Nestler EJ: Sustained hippocampal chromatin regulation in a mouse model of depression and antidepressant action. Nat Neurosci 2006, 9(4):519-525.

31. Avgustinovich DF, Kovalenko IL, Kudryavtseva NN: A model of anxious depression: persistence of behavioral pathology. Neurosci Behav Physiol 2005, 35(9):917-924.

32. Willner P: Chronic mild stress (CMS) revisited: consistency and behavioural-neurobiological concordance in the effects of CMS Neuropsychobiology 2005, 52(2):90-110.

33. Adamec RE, Blundell J, Burton P: Neural circuit changes mediating lasting brain and behavioral response to predator stress. Neurosci Biobehav Rev 2005, 29(8):1225-1241

34. Berton O, Durand M, Aguerre S, Mormede P, Chaouloff F: Behavioral, neuroendocrine and serotonergic consequences of single social defeat and repeated fluoxetine pretreatment in the Lewis rat strain. Neuroscience 1999, 92(1):327-341.

35. Mitra R, Jadhav S, McEwen BS, Vyas A, Chattarji S: Stress duration modulates the spatiotemporal patterns of spine formation in the basolateral amygdala. Proc Natl Acad Sci USA 2005, 102(26):9371-9376.

36. Chiba S, Numakawa T, Ninomiya M, Richards MC, Wakabayashi C, Kunugi H: Chronic restraint stress causes anxiety- and depression-like behaviors, downregulates glucocorticoid receptor expression, and attenuates glutamate release induced by brain-derived neurotrophic factor in the prefrontal cortex. Prog Neuropsychopharmacol Biol Psychiatry 2012, 39(1):112-119

37. Bland ST, Tamlyn JP, Barrientos RM, Greenwood BN, Watkins LR, Campeau S, Day HE, Maier SF: Expression of fibroblast growth factor-2 and brain-derived neurotrophic factor mRNA in the medial prefrontal cortex and hippocampus after uncontrollable or controllable stress. Neuroscience 2007, 144(4):1219-1228.

38. Duric $V$, Banasr M, Licznerski P, Schmidt HD, Stockmeier CA, Simen AA, Newton SS, Duman RS: A negative regulator of MAP kinase causes depressive behavior. Nat Med 2010, 16(11):1328-1332.

39. Surget A, Wang Y, Leman S, Ibarguen-Vargas Y, Edgar N, Griebel G, Belzung C, Sibille E: Corticolimbic transcriptome changes are state-dependent and region-specific in a rodent model of depression and of antidepressant reversal. Neuropsychopharmacology 2009, 34(6):1363-1380

40. Karssen AM, Her S, Li JZ, Patel PD, Meng F, Bunney WE Jr, Jones EG, Watson SJ, Akil H, Myers RM, et al: Stress-induced changes in primate prefrontal profiles of gene expression. Mol Psychiatry 2007, 12(12):1089-1102.

41. Orsetti M, Di Brisco F, Canonico PL, Genazzani AA, Ghi P: Gene regulation in the frontal cortex of rats exposed to the chronic mild stress paradigm, an animal model of human depression. Eur J Neurosci 2008, 27(8):2156-2164

42. da Huang W, Sherman BT, Lempicki RA: Systematic and integrative analysis of large gene lists using DAVID bioinformatics resources. Nat Protoc 2009, 4(1):44-57.

43. Huang Da W, Sherman BT, Zheng X, Yang J, Imamichi T, Stephens R, Lempicki RA: Extracting biological meaning from large gene lists with DAVID. Curr Protoc Bioinformatics 2009, Chapter 13:Unit 1311.
44. Dwivedi Y, Rizavi HS, Conley RR, Roberts RC, Tamminga CA, Pandey GN: Altered gene expression of brain-derived neurotrophic factor and receptor tyrosine kinase $B$ in postmortem brain of suicide subjects. Arch Gen Psychiatry 2003, 60(8):804-815.

45. Guilloux JP, Douillard-Guilloux G, Kota R, Wang X, Gardier AM, Martinowich K, Tseng GC, Lewis DA, Sibille E: Molecular evidence for BDNF- and GABA-related dysfunctions in the amygdala of female subjects with major depression. Mol Psychiatry 2011, doi:10.1038/mp.2011.113 [Epub ahead of print].

46. Bocchio-Chiavetto L, Bagnardi V, Zanardini R, Molteni R, Nielsen MG, Placentino A, Giovannini C, Rillosi L, Ventriglia M, Riva MA, et al: Serum and plasma BDNF levels in major depression: a replication study and meta-analyses. World J Biol Psychiatry 2010, 11(6):763-773.

47. Fuchikami M, Morinobu S, Segawa M, Okamoto Y, Yamawaki S, Ozaki N, Inoue T, Kusumi I, Koyama T, Tsuchiyama K, et al: DNA methylation profiles of the brain-derived neurotrophic factor (BDNF) gene as a potent diagnostic biomarker in major depression. PLoS One 2011, 6(8):e23881.

48. Roceri M, Cirulli F, Pessina C, Peretto P, Racagni G, Riva MA: Postnatal repeated maternal deprivation produces age-dependent changes of brain-derived neurotrophic factor expression in selected rat brain regions. Biol Psychiatry 2004, 55(7):708-714.

49. Naert G, Ixart G, Maurice T, Tapia-Arancibia L, Givalois L: Brain-derived neurotrophic factor and hypothalamic-pituitary-adrenal axis adaptation processes in a depressive-like state induced by chronic restraint stress. Mol Cell Neurosci 2011, 46(1):55-66.

50. Zhang Y, Gu F, Chen J, Dong W: Chronic antidepressant administration alleviates frontal and hippocampal BDNF deficits in CUMS rat. Brain Res 2010, 1366:141-148.

51. Altar CA, Cai N, Bliven $T$, Juhasz M, Conner JM, Acheson AL, Lindsay RM Wiegand SJ: Anterograde transport of brain-derived neurotrophic factor and its role in the brain. Nature 1997, 389(6653):856-860.

52. Smith MA, Makino S, Altemus M, Michelson D, Hong SK, Kvetnansky R, Post RM: Stress and antidepressants differentially regulate neurotrophin 3 mRNA expression in the locus coeruleus. Proc Natl Acad Sci USA 1995, 92(19):8788-8792

53. Roceri M, Hendriks W, Racagni G, Ellenbroek BA, Riva MA: Early maternal deprivation reduces the expression of BDNF and NMDA receptor subunits in rat hippocampus. Mol Psychiatry 2002, 7(6):609-616.

54. Marmigere F, Givalois L, Rage F, Arancibia S, Tapia-Arancibia L: Rapid induction of BDNF expression in the hippocampus during immobilization stress challenge in adult rats. Hippocampus 2003, 13(5):646-655.

55. Rage F, Givalois L, Marmigere F, Tapia-Arancibia L, Arancibia S: Immobilization stress rapidly modulates BDNF mRNA expression in the hypothalamus of adult male rats. Neuroscience 2002, 112(2):309-318.

56. Huang EJ, Reichardt LF: Trk receptors: roles in neuronal signal transduction. Annu Rev Biochem 2003, 72:609-642.

57. Minichiello L: TrkB signalling pathways in LTP and learning. Nat Rev Neurosci 2009, 10(12):850-860.

58. Genoud C, Knott GW, Sakata K, Lu B, Welker E: Altered synapse formation in the adult somatosensory cortex of brain-derived neurotrophic factor heterozygote mice. J Neurosci 2004, 24(10):2394-2400.

59. Minichiello L, Korte M, Wolfer D, Kuhn R, Unsicker K, Cestari V, Rossi-Arnaud C, Lipp HP, Bonhoeffer T, Klein R: Essential role for TrkB receptors in hippocampus-mediated learning. Neuron 1999, 24(2):401-414

60. Abidin I, Kohler T, Weiler E, Zoidl G, Eysel UT, Lessmann V, Mittmann T: Reduced presynaptic efficiency of excitatory synaptic transmission impairs LTP in the visual cortex of BDNF-heterozygous mice. Eur J Neurosci 2006, 24(12):3519-3531.

61. Chourbaji S, Brandwein C, Vogt MA, Dormann C, Hellweg R, Gass P: Nature vs. nurture: can enrichment rescue the behavioural phenotype of BDNF heterozygous mice? Behav Brain Res 2008, 192(2):254-258.

62. Sengupta S, Peterson TR, Sabatini DM: Regulation of the mTOR complex 1 pathway by nutrients, growth factors, and stress. Mol Cell 2010, 40(2):310-322

63. Hoeffer CA, Klann E: mTOR signaling: at the crossroads of plasticity, memory and disease. Trends Neurosci 2010, 33(2):67-75.

64. Jope RS: Glycogen synthase kinase- 3 in the etiology and treatment of mood disorders. Front Mol Neurosci 2011, 4:16 
65. Beurel E, Song L, Jope RS: Inhibition of glycogen synthase kinase-3 is necessary for the rapid antidepressant effect of ketamine in mice. Mol Psychiatry 2011, 16(11):1068-1070.

66. Karege F, Perroud N, Burkhardt S, Schwald M, Ballmann E, La Harpe R, Malafosse A: Alteration in kinase activity but not in protein levels of protein kinase $B$ and glycogen synthase kinase-3beta in ventral prefrontal cortex of depressed suicide victims. Biol Psychiatry 2007, 61(2):240-245

67. Li X, Zhu W, Roh MS, Friedman AB, Rosborough K, Jope RS: In vivo regulation of glycogen synthase kinase-3beta (GSK3beta) by serotonergic activity in mouse brain. Neuropsychopharmacology 2004, 29(8):1426-1431.

68. Wilkinson MB, Dias C, Magida J, Mazei-Robison M, Lobo M, Kennedy P, Dietz D, Covington H 3rd, Russo S, Neve R, et al: A novel role of the WNT-dishevelled-GSK3beta signaling cascade in the mouse nucleus accumbens in a social defeat model of depression. J Neurosci 2011, 31(25):9084-9092.

69. Jope RS, Johnson GV: The glamour and gloom of glycogen synthase kinase-3. Trends Biochem Sci 2004, 29(2):95-102.

70. Okamoto H, Voleti B, Banasr M, Sarhan M, Duric V, Girgenti MJ, Dileone RJ, Newton SS, Duman RS: Wnt2 expression and signaling is increased by different classes of antidepressant treatments. Biol Psychiatry 2010, 68(6):521-527.

71. Otsuki K, Uchida S, Watanuki T, Wakabayashi Y, Fujimoto M, Matsubara T, Funato $\mathrm{H}$, Watanabe $\mathrm{Y}$ : Altered expression of neurotrophic factors in patients with major depression. J Psychiatr Res 2008, 42(14):1145-1153.

72. Dwivedi Y, Rizavi HS, Zhang H, Mondal AC, Roberts RC, Conley RR, Pandey GN: Neurotrophin receptor activation and expression in human postmortem brain: effect of suicide. Biol Psychiatry 2009, 65(4):319-328.

73. Karege F, Vaudan G, Schwald M, Perroud N, La Harpe R: Neurotrophin levels in postmortem brains of suicide victims and the effects of antemortem diagnosis and psychotropic drugs. Brain Res Mol Brain Res 2005, 136(1-2):29-37.

74. Hock C, Heese K, Muller-Spahn F, Huber P, Riesen W, Nitsch RM, Otten U: Increased cerebrospinal fluid levels of neurotrophin 3 (NT-3) in elderly patients with major depression. Mol Psychiatry 2000, 5(5):510-513.

75. Coppell AL, Pei Q, Zetterstrom TS: Bi-phasic change in BDNF gene expression following antidepressant drug treatment. Neuropharmacology 2003, 44(7):903-910.

76. Nestler EJ, Hyman SE: Animal models of neuropsychiatric disorders. Nat Neurosci 2010, 13(10):1161-1169.

77. Christiansen SH, Olesen MV, Wortwein G, Woldbye DP: Fluoxetine reverts chronic restraint stress-induced depression-like behaviour and increases neuropeptide $\mathrm{Y}$ and galanin expression in mice. Behav Brain Res 2011, 216(2):585-591.

78. Reid S, Barbui C: Long term treatment of depression with selective serotonin reuptake inhibitors and newer antidepressants. BMJ 2010, 340:c1468.

79. McNamara RK, Able JA, Rider T, Tso P, Jandacek R: Effect of chronic fluoxetine treatment on male and female rat erythrocyte and prefrontal cortex fatty acid composition. Prog Neuropsychopharmacol Biol Psychiatry 2010, 34(7):1317-1321.

80. Thompson MR, Li KM, Clemens KJ, Gurtman CG, Hunt GE, Cornish JL, McGregor IS: Chronic fluoxetine treatment partly attenuates the long-term anxiety and depressive symptoms induced by MDMA ('Ecstasy') in rats. Neuropsychopharmacology 2004, 29(4):694-704.

81. Paxinos $G$, Watson C: The rat brain in stereotaxic coordinates. 6th edition. London: Academic Press, Elsevier; 2007.

82. Brown AL, Smith DW: Improved RNA preservation for immunolabeling and laser microdissection. RNA 2009, 15(12):2364-2374.

83. Schmittgen TD, Livak KJ: Analyzing real-time PCR data by the comparative C(T) method. Nat Protoc 2008, 3(6):1101-1108.

doi:10.1186/1471-2202-13-125

Cite this article as: Barreto et al:: Fluoxetine prevents development of an early stress-related molecular signature in the rat infralimbic medial prefrontal cortex. Implications for depression?. BMC Neuroscience 2012 13:125.

\section{Submit your next manuscript to BioMed Central and take full advantage of:}

- Convenient online submission

- Thorough peer review

- No space constraints or color figure charges

- Immediate publication on acceptance

- Inclusion in PubMed, CAS, Scopus and Google Scholar

- Research which is freely available for redistribution 